\title{
Behaviour of metallic anchorage plates for prestressing CFRP laminates under room and elevated temperatures
}

\author{
José Sena-Cruz, Luís Correia \\ ISISE, University of Minho, Guimarães, Portugal
}

\section{Cristina Barris}

AMADE, University of Girona, Girona, Spain

Contact: jsena@civil.uminho.pt

\begin{abstract}
The strengthening of reinforced concrete (RC) structures using fiber reinforced polymer (FRP) composites is a viable reality, consolidated by many studies and practical applications. One of the most common methods used to apply the FRP is the externally bonded reinforcement (EBR) technique. The development of stresses at the anchorage zones of the EBR-FRP composite might cause premature debonding. Two main situations required the use of mechanical systems to delay (or avoid) premature failure: (i) when the EBR-FRP systems are prestressed and (ii) when higher effective strain in passive EBR-FRP is required.

This works aims to assess the performance of a metallic anchorage plate commercially supplied by S\&P Clever Reinforcement Company by means of an experimental program composed of fourteen pull-out specimens (concrete/CFRP/anchorage).

Each metallic plate is fixed to the concrete element through six prestressed bolts, creating confinement in the anchorage region. All specimens are tested up to failure under two types of pullout configurations: (i) the steady-state temperature, where the laminate is pulled from the block with increasing force under constant temperature (of $20^{\circ} \mathrm{C}, 60^{\circ} \mathrm{C}$ and $80^{\circ} \mathrm{C}$ ); and, (ii) the transient temperature, where the laminate is pulled with constant force ( $0.5 \%$ and $0.6 \%$ of CFRP strain) and the temperature is gradually increased. Besides temperature and test configuration, the influence of the laminate width $(50 \mathrm{~mm}$ and $100 \mathrm{~mm}$ ) and level of transverse compression in the metallic plate (torque level of $30 \mathrm{~N} \cdot \mathrm{m}, 100 \mathrm{~N} \cdot \mathrm{m}$, and $150 \mathrm{~N} \cdot \mathrm{m}$ is applied in the anchorage bolts) were also studied.
\end{abstract}

Keywords: Bond Behaviour, CFRP, EBR, Transverse Compression, Elevated Temperature, Steady-state, Transient.

\section{Introduction}

Laminates and sheets made of fibre reinforced polymers (FRP) have become a viable alternative to material like steel and concrete for the strengthening of existing structures. Generally,
Carbon FRP (CFRP) in form of laminates are applied according to the externally bonded reinforcement (EBR) technique. Epoxy resins are mostly used to bond the CFRP laminate to concrete substrate because they provide the required load transfer between both materials [1-3]. The main problem 
of this technique is related to the development of high shear stresses and tensile stresses normal to the interface plan, located at the anchorage zone that provokes premature failure. The use of endanchorage system can delay or avoid the premature failure of the system. The load capacity of an EBR system without end-anchorages is limited by its effective bond length. However, with a mechanical anchorage (MA) the system's capacity can be improved even further when transverse confinement is applied, mainly because the confinement level enables friction in the cracked interface $[2,4,5]$. Another concern related to the EBR technique is the influence of moderate to high temperatures. The stiffness and strength of strengthening system can be severely deteriorated when the temperature gets close to the glass transition temperature $\left(T_{g}\right)$ of the epoxy adhesive. Considering that these temperatures are easily achieved in outdoor applications or in roof structures, the study on the behaviour of EBR systems under the effect of high temperatures is of utmost importance $[1,6]$.

This paper presents an experimental study on the bond behaviour of a commercially available mechanical anchorage (MA) system at room temperature and at elevated temperatures $\left(60^{\circ} \mathrm{C}\right.$ and $80^{\circ} \mathrm{C}$ ). The influence of the confinement level applied in the anchorage and the laminate geometry on the overall bond-slip response was also studied. The tests are described and the obtained results are critically analysed.

\section{Experimental investigation}

With the mind-set of studying the bond behaviour, fourteen prismatic concrete specimens $\left(200 \times 500 \times 800 \mathrm{~mm}^{3}\right)$ with EBR-CFRP laminates mechanically anchored to the concrete were tested under a pull-out test configuration. The mechanical anchorage plates are made of hard aluminium, have a thickness of $12 \mathrm{~mm}$ and section of $270 \times 200 \mathrm{~mm}^{2}$. Each anchorage plate has six holes of $18 \mathrm{~mm}$ of diameter to accommodate M16 8.8 bolt anchors. Three levels of transverse confinement were used through the torque level applied to the bolt anchors $(30 \mathrm{~N} \cdot \mathrm{m}, 100 \mathrm{~N} \cdot \mathrm{m}$ and $150 \mathrm{~N} \cdot \mathrm{m})$. The transverse confinement is also dependent on the laminate geometry and, in the present experimental work, two different CFRP laminates were used $\left(50 \times 1.2 \mathrm{~mm}^{2}\right.$ and $100 \times 1.2 \mathrm{~mm}^{2}$ ).

The specimens were grouped into three series (RT, ET and TR) as shown in Table 1. The specimens tested under a steady-state configuration at room temperature $\left(20^{\circ} \mathrm{C}\right)$ and at elevated temperatures $\left(60^{\circ} \mathrm{C}\right.$ and $\left.80^{\circ} \mathrm{C}\right)$ were grouped into series RT and $E T$, respectively. Series TR includes all specimens tested using a transient test configuration. Each specimen was labelled with a generic denomination: $\mathbf{L} \mathbf{X} \_T \mathbf{Y} \_\mathbf{Z}$, where $\mathbf{X}$ is the laminate width in [mm] (50 or 100), $\mathbf{Y}$ is the torque level in $[\mathrm{N} \cdot \mathrm{m}](30,100,150)$, and $\mathbf{Z}$ is the specimens' series (RT; ET1 for series ET tested at $60^{\circ} \mathrm{C}$; ET2 for series ET tested at $80^{\circ} \mathrm{C}$; T5 for series TR with the CFRP strain of $0.5 \%$; and T6 for series TR with the CFRP strain of $0.6 \%)$.

Table 1. Experimental program

\begin{tabular}{ccccc}
\hline Series & Specimen & $\begin{array}{c}\text { L. Width } \\
\text { [mm }]\end{array}$ & $\begin{array}{c}\text { Torque } \\
\text { [N.m] }\end{array}$ & Test Set-up \\
\hline RT & L50_T30_RT & 50 & 30 & Steady state \\
\hline RT & L50_T100_RT & 50 & 100 & Steady state \\
\hline RT & L50_T150_RT & 50 & 150 & Steady state \\
\hline RT & L100_T30_RT & 100 & 30 & Steady state \\
\hline RT & L100_T100_RT & 100 & 100 & Steady state \\
\hline RT & L100_T150_RT & 100 & 150 & Steady state \\
\hline ET & L100_T100_ET1 & 100 & 100 & Steady state \\
\hline ET & L100_T150_ET1 & 100 & 150 & Steady state \\
\hline ET & L100_T100_ET2 & 100 & 100 & Steady state \\
\hline ET & L100_T150_ET2 & 100 & 150 & Steady state \\
\hline TR & L100_T100_T5 & 100 & 100 & Transient \\
\hline TR & L100_T150_T5 & 100 & 150 & Transient \\
\hline TR & L100_T100_T6 & 100 & 100 & Transient \\
\hline TR & L100_T150_T6 & 100 & 150 & Transient \\
\hline & & & & \\
\hline
\end{tabular}




\subsection{Materials}

The mechanical and geometrical properties of all materials used the tests are presented in this section. The fourteen concrete specimens were casted in using two batches (B1 and B2). The elastic modulus $\left(E_{c}\right)$ and ultimate strength $\left(f_{c}\right)$ of the concrete were determined through compressive tests using the LNEC E397-1993:1993 and NP EN 12390-3:2011 recommendation, respectively. Six cylindrical samples of each batch $(150 \mathrm{~mm}$ of diameter and $300 \mathrm{~mm}$ of height) were tested at the same day of the pull-out tests. The results are shown in Table 2.

Table 2. Concrete properties. Note: the values between parentheses are the corresponding coefficients of variation (CoV).

\begin{tabular}{cccc}
\hline Series & Batch & $\begin{array}{c}\mathbf{E}_{\mathrm{c}} \\
{[\mathrm{GPa}]}\end{array}$ & $\begin{array}{c}\mathbf{f}_{\mathrm{c}} \\
{[\mathrm{MPa}]}\end{array}$ \\
\hline RT & B1 & $30.8(2.8 \%)$ & $33.4(4.3 \%)$ \\
\hline ET, TR & B2 & $32.8(0.7 \%)$ & $45.0(1.2 \%)$ \\
\hline
\end{tabular}

The elastic modulus $\left(E_{f}\right)$ and tensile strength $\left(f_{f}\right)$ of the CFRP laminates were assessed through the ISO 527-5:2009 recommendations. The CFRP laminates used in the present work came from three different CFRP lots. For each CFRP lot, six samples were tested, and the main results can be observed in Table 3.

Table 3. CFRP laminate properties. Note: the values between parentheses are the corresponding coefficients of variation (CoV).

\begin{tabular}{ccccc}
\hline Series & $\begin{array}{c}\text { CFRP Geometry } \\
\text { lot }\end{array}$ & $\begin{array}{c}\mathbf{E}_{\mathrm{f}} \\
{\left[\mathrm{mm}^{3}\right]}\end{array}$ & $\begin{array}{c}\mathbf{f}_{\mathrm{f}} \\
{[\mathrm{GPa}]}\end{array}$ & {$[\mathrm{MPa}]$} \\
\hline RT & A & $50 \times 1.2$ & $176.4(2.0 \%)$ & $2222.4(4.7 \%)$ \\
\hline RT & B & $100 \times 1.2$ & $169.4(1.4 \%)$ & $2480.2(4.0 \%)$ \\
\hline ET, TR & C & $100 \times 1.2$ & $187.2(0.9 \%)$ & $2895.2(4.4 \%)$ \\
\hline
\end{tabular}

The epoxy adhesive (type S\&P Resin 220), produced by the same supplier as for the CFRP laminate, was used as bond agent to fix the reinforcements to the concrete substrate. In the scope of the present work the epoxy adhesive was not characterized. Based on an assessment of its properties previously made in another experimental program, a modulus of elasticity of 7.2 GPa ( $\mathrm{CoV}=3.7 \%)$ and a tensile strength of $22.0 \mathrm{MPa}(\mathrm{CoV}=4.5 \%)$ are expected [7].

\subsection{Specimen preparation}

In the preparation of the specimens, the following procedures are followed:

i. The first step consisted on the surface preparation. The concrete surface was enhanced using the sandblasting technique and cleaned using pressurized air;

ii. Six holes were drilled to accommodate the M16 bolt anchors in each specimen. HIT-HY $200-A^{\circledR}$ chemical bond agent was used to fix the bolts to concrete;

iii. Then, the epoxy adhesive was prepared according to the requirements provided by the supplier and applied on the previously cleaned CFRP laminate strip. The adhesive is also applied on the concrete surface and on the surface of the metallic anchorage plate;

iv. The CFRP laminate strip was placed in its final position and slightly pressed against the concrete substrate;

v. Finally, the anchorage plate was placed in its predefined location and the M16 anchor bolts were torqued with the aid of a dynamometric key that ensured the target level of confinement. The specimens were ready to be tested after 7-14 days of curing at lab environment.

The final result was a concrete block with CFRP laminate bonded to the concrete block in a total length of $522 \mathrm{~mm}$, where $250 \mathrm{~mm}$ corresponded to the defined length of unconfined bonded region that follows the anchorage plate (length of $272 \mathrm{~mm}$ ). The unconfined bonded length surpasses the theoretical effective length $\left(l_{e}\right)$ needed to achieve the maximum debonding load (according to the CNR [8] $\left.\right|_{\mathrm{e}} \approx 200 \mathrm{~mm}$ ).

\subsection{Test configuration and Instrumentation}

The specimens' geometry, instrumentation and test configuration are shown in Figure 1. The 
instrumentation included: three linear variable differential transducers (see Figure 1a) to record the relative displacement of the CFRP laminate to the concrete surface at the loaded end (beginning of the bonded length - LVDT-1), at the mid-end (before the anchorage plate, at the end of the bonded length - LVDT-2) and at the free-end (after the anchorage plate); five strain gauges (S1-S5) evenly distributed on the bonded length (see Figure $1 b$ ) to measure the strain evolution; four thermocouples type $k$ to measure the temperature of the bonded length and inside the anchorage (see Figure 1a); and a load cell of $300 \mathrm{kN}$ to measure the applied pull-out load.

The behaviour of the strengthening system at elevated temperatures was assessed through a pull-out test performed for both steady-state and transient conditions. In the steady-state tests, each specimen was heated up to a predefined temperature $\left(60^{\circ} \mathrm{C}\right.$ and $80^{\circ} \mathrm{C}$ for series ET) and then loaded up to failure; whereas in the transient tests, the specimens were first loaded to predefined CFRP stress $(0.5 \%$ and $0.6 \%$ of CFRP strain for specimens with the suffix " $\mathrm{T} 4$ " and "T5", respectively) and then heated up to $80^{\circ} \mathrm{C}$. If, during a transient test, failure didn't occur when the temperature was being raised, the test conditions were kept constant (temperature of $80{ }^{\circ} \mathrm{C}$ and predefined CFRP stress) for a period of one hour. The elevated temperatures were achieved using an infra-red heating system. The heating system (see Figure 1a and Figure 1c) was composed of by four infra-red heaters controlled by a thermostat that measured the temperature in the anchorage region. This system was developed to achieve the predefined temperatures in the anchorage region within a relative short period of time (from $20^{\circ} \mathrm{C}$ to $80^{\circ} \mathrm{C}$ within 170 minutes), with a uniform distribution of infra-red radiation over the tested specimens. Because the different materials that composed the strengthening system had different thermal properties, the temperature measured in the bonded length was different than the temperature measured inside the anchorage. However, the temperature was uniform in all unconfined bonded region as it was uniform in the anchorage plate. When the temperature in the anchorage region was $60^{\circ} \mathrm{C}$ and $80^{\circ} \mathrm{C}$, the temperature in the bonded length region was $53^{\circ} \mathrm{C}$ and $66^{\circ} \mathrm{C}$, respectively.
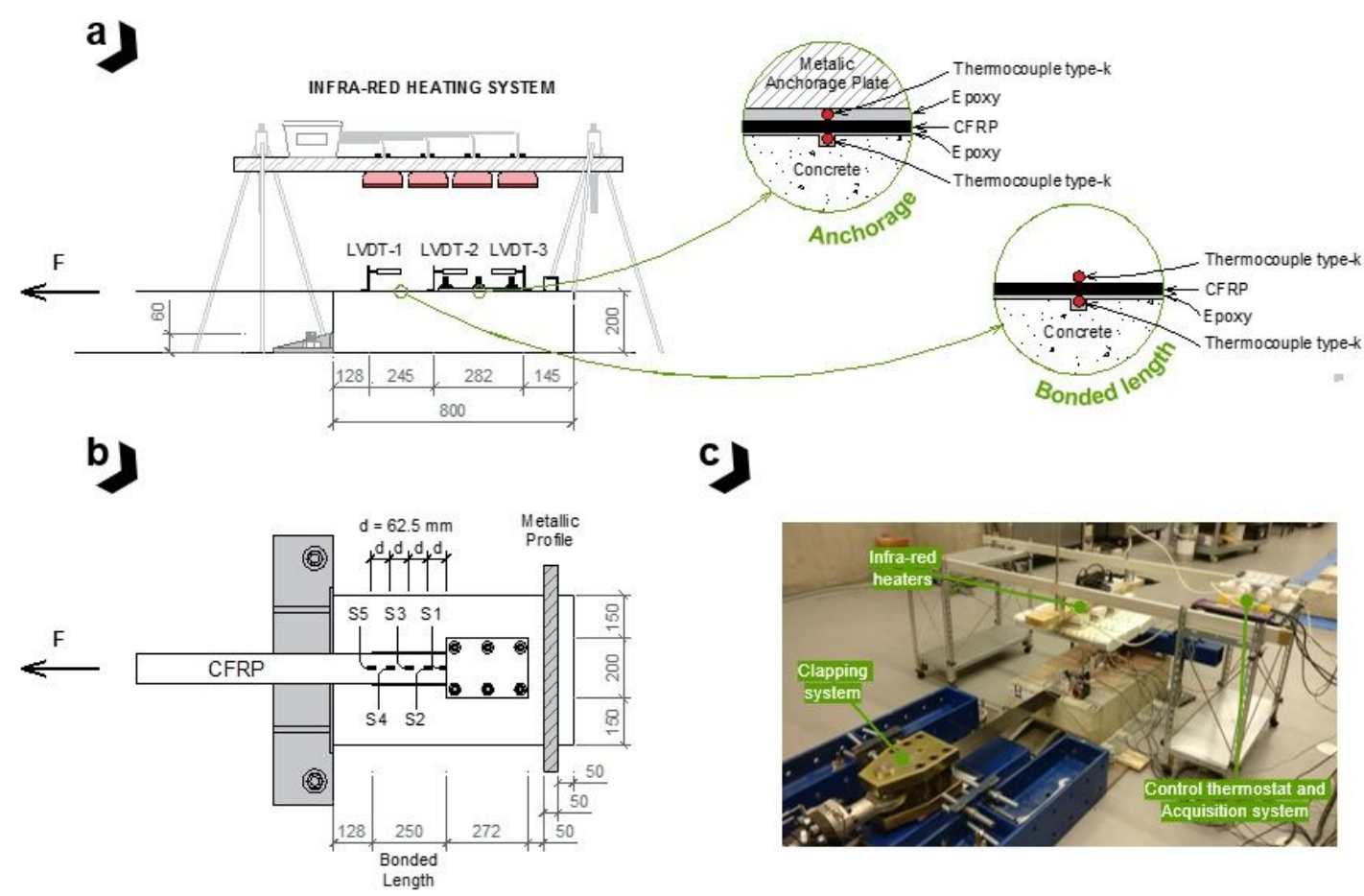

Figure 1. Set-up and instrumentation: (a) Side view, (b) top view and (c) photo of the heating system. 


\section{Results and discussion}

\subsection{Steady state tests}

Studies have shown that high temperatures can influence the stiffness and strength of EBR strengthening systems, especially when these systems are exposed to a temperature higher than the $T_{\mathrm{g}}$ of the epoxy adhesive. In order to investigate the temperature influence, steady state tests were carried out with the following three temperatures: $20^{\circ} \mathrm{C}$ (room temperature), to study the behaviour of the MA system at a temperature below the $T_{g}$ of the epoxy adhesive; $60^{\circ} \mathrm{C}$, to study the behaviour of the MA system at a temperature around the $T_{g}$ of the epoxy adhesive; and $80^{\circ} \mathrm{C}$, to study the behaviour of the MA system at a temperature above the $T_{\mathrm{g}}$ of the epoxy adhesive.

\subsubsection{Load-slip behaviour}

Figure 2 shows the load-slip behaviour of two specimens, the L100_T100_RT and the L100_T100_ET1. The response of the MA system observed in specimens L100_T100_RT and L100_T100_ET1 is representative of the behaviour seen in across series RT and ET, respectively. For both series, the pull-out test started with an almost linear branch at the loaded end. Then the debonding of the laminate from the concrete substrate starts to occur and, in the loaded end, the registered slip increases while the load level remains almost constant. The complete debonding of the FRP is observed when the mid end LVDT starts to register displacements. From this point onwards, the slip increases in both locations (loaded end and mid end) and all the pull-out load is supported by the mechanical anchorage. At this stage of the test, different behaviours are observed in both series: in series RT the load and slip increase until rupture of the CFRP is attained. During this period, the LVDT-3 does not register any slip displacement. However, in series ET the load and slip at the loaded end and the mid end increase until slippage in the anchorage is observed. Immediately afterwards, the relative displacement at the free end starts to increase and, simultaneously, the load decreases. In contrast to series RT, where the failure is a fragile event and the supported load decreases from its maximum to null instantly, series ET exhibits a failure with a high degree of deformability where the load does not decrease to zero, but stabilizes at a load level that represents a residual and constant bond stress. Similar results have been observed in the literature $[2,4]$.

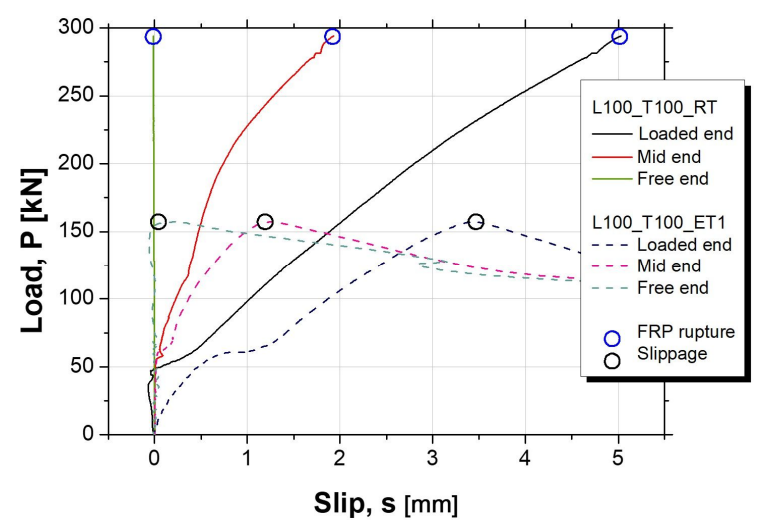

Figure 2. Load-slip behaviour for specimens L100_T100_RT and L100_T100_ET1.

\subsubsection{Debonding}

The main results obtained during the steady state tests are presented in Figure 3. According to the CNR [8], the effective bond length $\left(\mathrm{l}_{\mathrm{e}}\right)$ for the tested specimens equals to $200 \mathrm{~mm}$. As mentioned before, each specimen has an unconfined bonded region of $250 \mathrm{~mm}$ which means that the maximum debonding load can be attained. In the current experimental programme, the debonding load corresponds to the maximum load that is supported by the bonded length, before the metallic anchorage starts to be solicited to support the pull-out force. In series RT the debonding load could be identified by the load for which LVDT-2 starts to register displacements. At the same instant, the strain gauge closest to the anchorage plate ( $\mathrm{S} 1$, see Figure 1) registers an abrupt increase of strain. In general, for series RT, strain gauge $\mathrm{S} 1$ presented null values until the debonding initiation as seen in other research works [6]. In average, the debonding load ( $\mathrm{P}_{\mathrm{deb}}$ ) observed in series $\mathrm{RT}$ is equal to $48.7 \mathrm{kN}$ and $25.9 \mathrm{kN}$ for laminates with the cross section of $100 \times 1.2 \mathrm{~mm}^{2}$ and $50 \times 1.2 \mathrm{~mm}^{2}$, respectively. As expected, the width of the CFRP laminate $(w)$ is an important factor on the debonding load and a relation between $\mathrm{W}$ and $\mathrm{P}_{\text {deb }}$ is observed ( $\left.P_{\text {deb }} / w=0.5 \mathrm{kN} / \mathrm{mm}, \mathrm{CoV}=9.8 \%\right)$. In addition, the expected debonding load was computed based on the CNR [8] guidelines. For 
laminate of $100 \times 1.2 \mathrm{~mm}^{2}$ the expected debonding load is $53.0 \mathrm{kN}$ and for the laminate of $50 \times 1.2 \mathrm{~mm}^{2}$ the expected $P_{\text {deb }}$ is $27.0 \mathrm{kN}$. This shows that the experimental results are in accordance with the expected values.

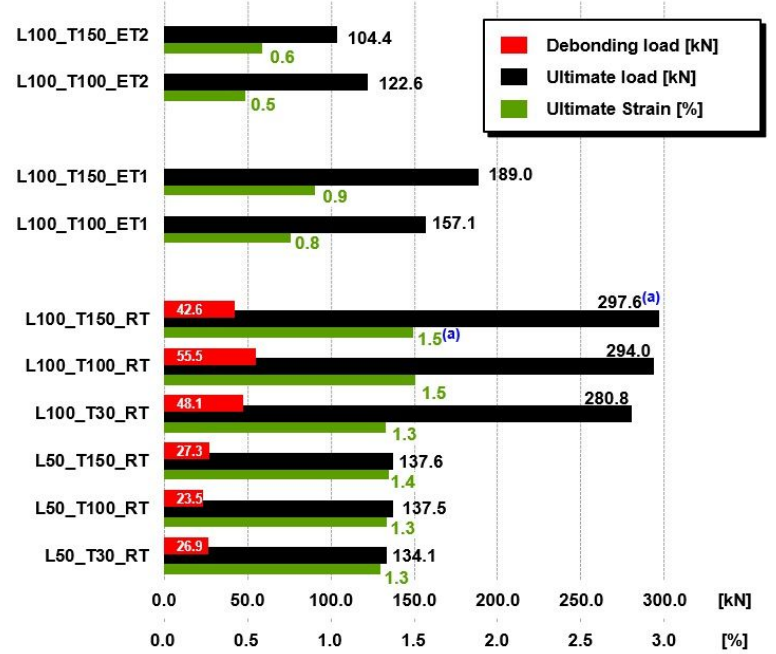

Figure 3. Main Results for steady State Tests. Note: ${ }^{(a)}$ the ultimate load was not registered due to a technical problem - these values correspond to the theoretically expected results.

In series ET, the debonding load could not be as easily identified as it was with series RT. Figure 4 shows the typical strain evolution across the bonded length of specimens tested at elevated temperatures. In series ET, all specimens showed an almost linear strain evolution with the load on the loaded end (location $\mathrm{x}=0 \mathrm{~mm}$, see Figure 4 ) and a gradual decrease towards the anchorage plate (location $x=250 \mathrm{~mm}$, see Figure 4). All strain gauges showed an increasing strain variation since early load stages, even in the strain gauge S1.

The difference between series $\mathrm{RT}$ and ET resides in the fact that the test temperature changed the properties of the epoxy adhesive. In two recent studies carried out by the authors $[7,9]$ the S\&P Resin 220 was characterized and the adhesive's $T_{g}$ varied between $47^{\circ} \mathrm{C}$ and $52^{\circ} \mathrm{C}$ (epoxy cured at room temperature before testing). Series ET was carried out at the temperatures of $60^{\circ} \mathrm{C}$ and $80^{\circ} \mathrm{C}$ and, for that reason, it is expected that the epoxy adhesive is in a viscous state. This reduction in the adhesive stiffness might be responsible for smoothing the shear stress/strain distribution.

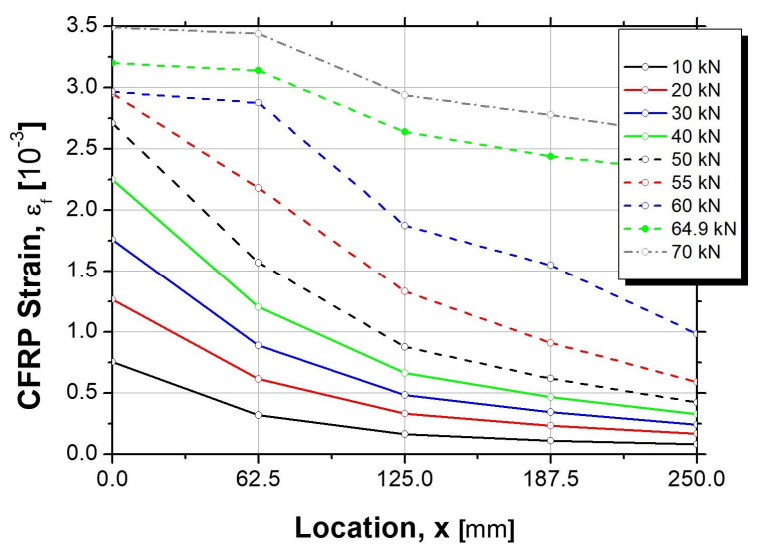

Figure 4. Strain profile of specimen L100_T150_ET2.

\subsubsection{Failure Modes}

Two failure modes were observed in the steady state tests: CFRP rupture and anchorage slippage. These two types of failure are shown in Figure 5. CFRP rupture (see Figure 5a) was attained when the pull-out force matched the maximum tensile force supported by the laminate. This type of failure was observed in all specimens from series RT. In series ET all specimens failed by anchorage slippage (see Figure 5b). As referred before, the test temperature influenced the epoxy adhesive's properties and, consequently changed the specimen's failure mode.

The change of failure modes can be noticed in the ultimate parameter, mainly in the ultimate load $\left(P_{u}\right)$ and strain $\left(\varepsilon_{u}\right)$. Whereas CFRP rupture is marked by reaching the maximum tensile load and strain of the CFRP (Laminate $100 \times 1.2 \mathrm{~mm}^{2}$ : $\mathrm{P}_{\mathrm{u}}=290.8 \mathrm{kN}$ and $\varepsilon_{\mathrm{u}}=1.4 \%$; Laminate $50 \times 1.2 \mathrm{~mm}^{2}$ : $\mathrm{P}_{\mathrm{u}}=136.4 \mathrm{kN}$ and $\varepsilon_{\mathrm{u}}=1.3 \%$ ), the anchorage slippage occurred when the load was $58.5-44.5 \%$ of the CFRP maximum tensile capacity. In addition, the ultimate parameters in series ET are highly influenced by the level of confinement in the anchorage region: the increase of torque from $100 \mathrm{~N} \cdot \mathrm{m}$ to $150 \mathrm{~N} \cdot \mathrm{m}$ lead to an average increase of $20.3 \%$ and $14.5 \%$ in the $\mathrm{P}_{\mathrm{u}}$ of specimens tested at $60^{\circ} \mathrm{C}$ and $80^{\circ} \mathrm{C}$, respectively. Nevertheless, the temperature is the major influential factor in all ultimate parameters, as can be seen in Figure 3 .

The failure by anchorage slippage did not result in a swift decrease of load down to zero, but to a softened reduction of the supported load down to a residual value of $60.5-66.2 \%$ of its ultimate load. The residual value is a consequence of the 
transverse confinement stresses applied on the anchorage region. For that reason, the specimens with the torque of $150 \mathrm{~N} \cdot \mathrm{m}$ showed higher residual capacity (125.1 kN and $84.9 \mathrm{kN}$ for specimens L100_T150_ET1 and L100_T150_ET2, respectively) than specimens with the torque of $100 \mathrm{~N} \cdot \mathrm{m}$ $(103.3 \mathrm{kN}$ and $75.7 \mathrm{kN}$ for specimens L100_T100_ET1 and L100_T100_ET2, respectively).
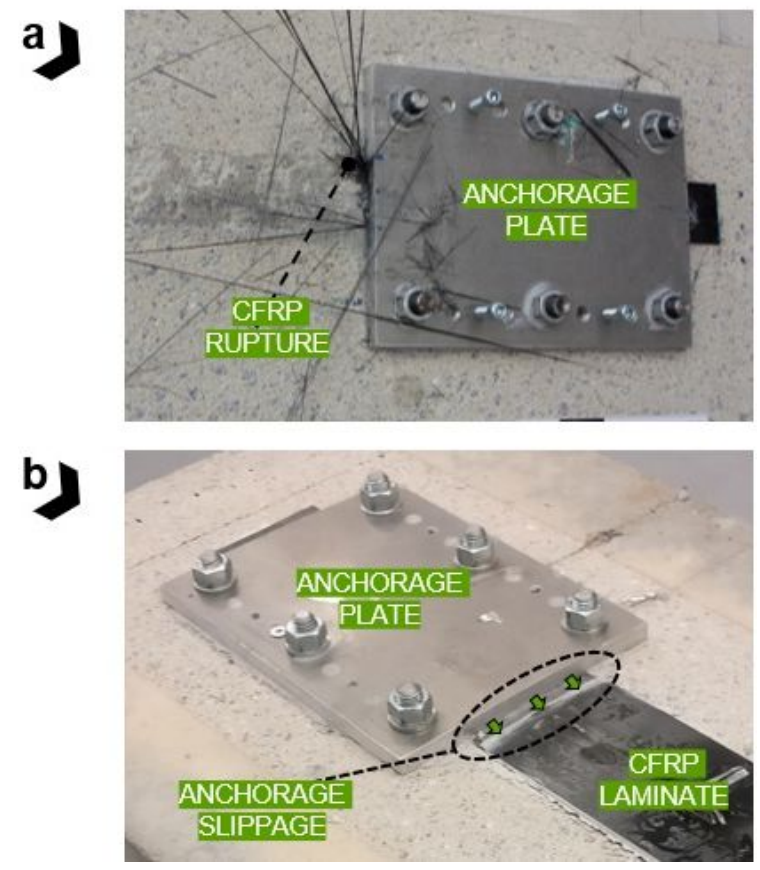

Figure 5. Failure modes observed: (a) in specimen L50_T150_RT and (b) in specimen L100_T150_ET2.

\subsection{Transient tests}

In the transient tests, two specific stress levels were imposed to the CFRP laminate and, for each stress level, it was possible to observe the maximum temperature supported. The slip evolution in the loaded end and free end with the temperature is shown in Figure 6 for specimens tested at a constant strain level of $0.5 \%$ and $0.6 \%$. Figure 5 also shows the time when the maximum predefined temperature was reached $\left(t_{f}\right)$ and when failure was observed $\left(t_{u}\right)$ in minutes. It should be pointed out that in this analysis, the reference of time ( $t=0 \mathrm{~min}$ ) corresponds to the heating initiation. Slippage from the anchorage was the failure mode observed in all specimens tested under the transient configuration (see Figure 6b).

The lowest stress level used in the transient tests corresponded to $0.5 \%$ of CFRP strain. For this specific stress level, the confinement level induced by the level of torque proves to be a major factor in the anchorage capacity: the specimen with the lowest torque level (L100_T100_T5) failed when the temperature reached $67.7^{\circ} \mathrm{C}$, whereas the specimen L100_T150_T5 not only supported the highest predefined temperature $\left(80^{\circ} \mathrm{C}\right)$ but also endured almost one hour at those conditions before slippage failure. The remaining two specimens, tested with the highest stress level of $0.6 \%$ of CFRP strain, failed shortly after the temperature in the anchorage surpassed the adhesive $T_{\mathrm{g}}$. The specimen L100_T150_T6 failed at $64.2^{\circ} \mathrm{C}$ and the specimen L100_T100_T6 failed at $63.4^{\circ} \mathrm{C}$. For this specific stress level, the confinement level has a considerable lower influence in the anchorage resistance when compared with the specimens with the stress level of $0.5 \%$ of the CFRP strain.

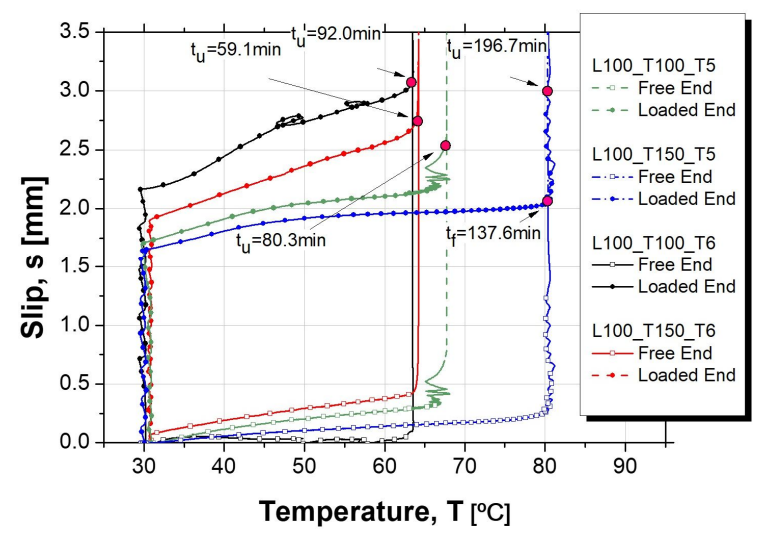

Figure 6. Slip evolution with the temperature variation for series TR.

\section{Conclusions}

This paper presented results of an experimental study about the bond performance of a mechanical anchorage of EBR CFRP system to concrete structures. The results obtained allow drawing the following main conclusions: (i) the mechanical anchorage showed adequate transverse confinement of the laminate to the concrete substrate at room temperature. Regardless of the level of confinement $(100 \mathrm{~N} \cdot \mathrm{m}$ or $150 \mathrm{~N} \cdot \mathrm{m})$, the anchorage allowed the use of the maximum capacity of the CFRP laminate; (ii) all specimens tested at room temperature (series RT) failed by CFRP rupture at its maximum tensile capacity, whereas all specimens tested at elevated temperatures (series ET and TR) failed by 
anchorage slippage; (iii) the ultimate load observed in series ET corresponds to $41.5-63.5 \%$ of the average value obtained in series RT (same CFRP geometry); (iv) at room temperature, the debonding load increased with the laminate width and a good correlation between the experimental values and the prediction from the literature; (v) transient tests carried out with the lowest stress level ( $0.5 \%$ of CFRP strain) failed by anchorage slippage, but the confinement level played a critical role in the anchorage capacity; (vi) transient tests carried out with highest stress level (0.6\% of CFRP strain) lead to the anchorage failure shortly after reaching the adhesives $\mathrm{T}_{\mathrm{g}}$; (vii) based on the results from both test configurations, the torque level appears to be a relevant factor in increasing the anchorage capacity.

\section{Acknowledgements}

This work was supported by FEDER funds through the Operational Program for Competitiveness Factors - COMPETE and National Funds through FCT (Portuguese Foundation for Science and Technology) under the project FRPLongDur POCI01-0145-FEDER-016900 (FCT PTDC/ECMEST/1282/2014) and partly financed by the project POCI-01-0145-FEDER-007633. The second author wish also to acknowledge the grant SFRH/BD/98309/2013 provided by FCT. The third author acknowledges the Spanish Government (Ministerio de Educación, Cultura y Deporte) for the grant José Castillejo ref. CAS16/00288. Finally, the authors also like to thank the S\&P Clever Reinforcement Ibérica Lda. company for providing the materials.

\section{References}

[1] ACl 440.2R-08. Guide for the design and construction of externally bonded FRP systems for strengthening existing structures. ACl committee 4402008.

[2] Correia L, Sena-Cruz J., Michels J., França P., Pereira E., Escusa G. Durability of RC slabs strengthened with prestressed CFRP laminate strips under different environmentaland loading conditions. Compos PartB Eng [Internet]. 2017;125(Supplement C):71-88. Available from:

http://www.sciencedirect.com/science/article/pii/S135983681730433X

[3] Michels J., Sena-Cruz J., Christen R., Czaderski C., Motavalli
M. Mechanical performance of cold-curing epoxy adhesives after different mixing and curing procedures. Compos Part B Eng [Internet]. 2016;98:434-43. Available from: http://dx.doi.org/10.1016/.j.compositesb.2016.05.054

[4] Biscaia HC., Chastre C., Silva MAG. Bond-slip model for FRP-to-concrete bonded joints under external compression. Compos Part B Eng [Internet]. 2015;80(Supplement $\quad$ C):246-59. Available from: http://www.sciencedirect.com/science/article/pii/S1359836815003674

[5] fib Model Code for Concrete Structures 2010. fib Model Code for Concrete Structures 2010. 2013.

[6] Firmo JP., Correia JR., Pitta D., Tiago C., Arruda MRT. Experimental characterization of the bond between externally bonded reinforcement (EBR) CFRP strips and concrete at elevated temperatures. Cem Concr Compos [Internet]. 2015;60(SupplementC):44-54. Available from: http://mww.sciencedirect.com/science/article/pii/S0958946515000505

[7] Silva P., Fernandesa P., Sena-Cruza J., Xavier J., Castro F., Soares D., et al. Effects of different environmental conditions on themechanical characteristics of a structural epoxy. Compos Part B Eng [Internet]. 2016 Mar 1 [cited 2017 Nov 21];88:55-63. Available from: http://mwn.sciencedirect.com/science/artide/pii/S1359836815006666

[8] CNR. Guide for the design and construction of externally bonded FRP systems for strengthening existing structures. 2013.

[9] Emara M., Torres L, Baena M., Barris C., Moawad M. Effect of sustained loading and environmental conditions on the creep behavior of an epoxy adhesive for concrete structures strengthened with CFRP laminates. Compos Part B Eng [Internet]. 2017;129(Supplement C):88-96. Available from: http://mww.sciencedirect.com/science/artide/pii/S135983681731764X 